\title{
Herb-drug Pharmacokinetic Interaction between Carica Papaya Extract and Amiodarone in Rats
}

\author{
Márcio Rodrigues ${ }^{\mathrm{a}, \mathrm{b}, \mathrm{c}}$, Gilberto Alves ${ }^{\mathrm{c}, \mathrm{b},}$, Joana Francisco ${ }^{\mathrm{c}}$, Ana Fortuna ${ }^{\mathrm{a}, \mathrm{b}}$, Amílcar Falcão ${ }^{\mathrm{a}, \mathrm{b}}$ \\ ${ }^{\text {a }}$ Laboratory of Pharmacology, Faculty of Pharmacy, University of Coimbra, Pólo das Ciências da Saúde, Azinhaga de \\ Santa Comba, Coimbra, Portugal. \\ ${ }^{\mathrm{b}} \mathrm{CNC}-$ Centre for Neuroscience and Cell Biology, University of Coimbra, Coimbra, Portugal. \\ ${ }^{c}$ CICS-UBI - Health Sciences Research Centre, University of Beira Interior, Av. Infante D. Henrique, Covilhã, \\ Portugal.
}

Received, March 3, 2014; revised, June 3, 2014; accepted, July 10, 2014; July 13, 2014.

\begin{abstract}
Purpose - Carica papaya has been traditionally used worldwide in folk medicine to treat a wide range of ailments in humans, including the management of obesity and digestive disorders. However, scientific information about its potential to interact with conventional drugs is lacking. Thus, this work aimed to investigate the interference of a standardized C. papaya extract (GMP certificate) on the systemic exposure to amiodarone (a narrow therapeutic index drug) in rats. Methods - In the first pharmacokinetic study, rats were simultaneously co-administered with a single-dose of C. papaya $(1230 \mathrm{mg} / \mathrm{kg}$, p.o.) and amiodarone $(50 \mathrm{mg} / \mathrm{kg}$, p.o.); in the second study, rats were pre-treated for 14 days with C. papaya (1230 $\mathrm{mg} / \mathrm{kg} / \mathrm{day}$, p.o.) and received amiodarone $\left(50 \mathrm{mg} / \mathrm{kg}\right.$, p.o.) on the $15^{\text {th }}$ day. Rats of the control groups received the herbal extract vehicle. Blood samples were collected before dosing and at $0.25,0.5,1,2,4,6,8$ and $12 \mathrm{~h}$ following amiodarone administration; in addition, at $24 \mathrm{~h}$ post-dose, blood and tissues (heart, liver, kidneys and lungs) were also harvested. Thereafter, the concentrations of amiodarone and its major metabolite (mono- $N$-desethylamiodarone) were determined in plasma and tissue samples employing a highperformance liquid chromatography-diode array detection method previously developed and validated. Results - In both studies was observed a delay in attaining the maximum plasma concentrations of amiodarone $\left(t_{\max }\right)$ in the rats treated with the extract. Nevertheless, it must be highlighted the marked increase (60-70\%) of the extent of amiodarone systemic exposure (as assessed by $\mathrm{AUC}_{0-\mathrm{t}}$ and $\mathrm{AUC}_{0-\infty}$ ) in the rats pre-treated with $C$. papaya comparatively with the control (vehicle) group. Conclusions - The results herein found suggest an herb-drug interaction between $C$. papaya extract and amiodarone, which clearly increase the drug bioavailability. To reliably assess the clinical impact of these findings appropriate human studies should be conducted.
\end{abstract}

This article is open to POST-PUBLICATION REVIEW. Registered readers (see "For Readers") may comment by clicking on ABSTRACT on the issue's contents page.

\section{INTRODUCTION}

Carica papaya, also traditionally known as pawpaw or papaya, is a tree-like herbaceous plant belonging to the family of Caricaceae $(1,2)$. Due to its edible fruits, C. papaya is widely cultivated in several tropical, sub-tropical and temperate regions, including Australia, Brazil, China, Hawaii, Malaysia and India (1,3). Different parts of the plant (fruits, leaves, barks, roots, flowers, seeds, and latex) as well as some of their extracts have been traditionally used worldwide in folk medicine to treat a wide range of ailments in humans (4-7). Indeed, nowadays C. papaya is considered a nutraceutical plant due to its various medicinal properties $(5,6,8)$.

The fruits of $C$. papaya are one of the most commonly consumed throughout the world (9), constituting a rich nutritional source of fibre, minerals and antioxidant nutrients (2). More specifically, papaya fruit is a good source of bioactive phytochemicals, including carotenoids ( $\beta$-carotene, $\alpha$-carotene, $\beta$-cryptoxanthin, $\alpha$ cryptoxanthin, lutein, 9-cis- $\beta$-carotene), phenolic compounds (ferulic acid, caffeic acid, $p$-coumaric acid, rutin, quercetin, kaempferol) and glucosinolates (benzyl glucosinolate, benzyl isothiocyanate) (7). Unripe pulp of C. papaya also contains cardenolides which seem to have medicinal value for the treatment of congestive heart failure (4).

\footnotetext{
Corresponding Author: Gilberto Alves, Faculty of Health Sciences, University of Beira Interior CICS-UBI - Health Sciences Research Centre, University of Beira Interior Av. Infante D. Henrique Covilhã, Portugal. E-mail address: gilberto@fcsaude.ubi.pt
} 
Additionally, among other biologically active constituents, papaya also includes cysteine proteinases as chymopapain and papain $(2,10)$, whose biological activity is often analyzed through the proteolytic activity, particularly the papain activity (4).

The extracts of ripe fruits are used for a variety of medicinal purposes including the treatment of ringworm, malaria, hypertension (2), whereas extracts of unripe fruits have been used in the treatment of ulcers (11) and diabetes (2). In addition, the hypoglycemic and hypolipidemic effects of the aqueous seed extract of $C$. papaya in rats have also been reported (12). The ethanolic extract and water-soluble fraction of $C$. papaya also showed anti-hyperlipidemic activity in olivetreated rats (13). More recently, Athesh et al. (9) reported the anti-obesity effect of the aqueous fruit extract of $C$. papaya in rats fed on high fat cafeteria diet. Effectively, besides the proteolytic enzymes, chymopapain and papain, C. papaya also has a lipase enzyme that can contribute to its lipolytic action, supporting its use in the management of obesity and digestive disorders $(2,10,14)$.

Despite the use of medicinal herbs since ancient times (15), a dramatic increase of their use around the world has occurred in the last years (16). Since phytochemicals are handled in the body through the same type of mechanisms involved in drug biodisposition, there is an increased risk for herb-drug interactions (17). Importantly, $C$. papaya extract was associated to an increase of the international normalized ratio (INR) in a patient taking warfarin concomitantly (18). Hence, it has been suggested that C. papaya is contraindicated in patients under warfarin therapy $(18,19)$.

Bearing in mind that obesity and overweight are increasing at an alarming rate worldwide (20), representing the major independent risk factors for cardiovascular diseases (21-23), and considering the anti-obesity effects recently reported for the aqueous fruit extract of $C$. papaya) (9), an increase in the consumption of herbal supplements containing $C$. papaya is expected. Thus, as the occurrence of herb-drug interactions represents a major safety concern, especially when the affected (object) drug has a narrow therapeutic index $(24,25)$, it is pertinent to investigate the potential for the occurrence of pharmacokinetic-based interactions between $C$. papaya extract and amiodarone (a narrow therapeutic index drug).

Actually, despite its narrow therapeutic index, amiodarone $[2-n-$ butyl $-3-(3,5-$ diiodo -4 -diethylaminoethoxy-benzoyl)-benzofuran;

(Figure 1)] is one of the antiarrhythmic agents most widely prescribed (26). Furthermore, the pharmacokinetics of amiodarone and its main metabolite, mono- $N$-desethylamiodarone (MDEA; Figure 1), is complex and has shown large interindividual variability $(27,28)$. In fact, amiodarone has a variable oral bioavailability and undergoes extensive enterohepatic recirculation (28); moreover, the parent drug and its main metabolite are highly lipophilic and tend to extensively accumulate in several tissues (29). On the other hand, amiodarone has been associated with a variety of life-threatening adverse events, including thyroid dysfunction, pulmonary toxicity and hepatic toxicity (29-31), and relevant clinical drug interactions have been reported (32-35). Thus, taking into account all the reasons aforementioned, this work was planned in order to investigate if a standardized extract of the fruit of $C$. papaya influence the rate and extent of amiodarone exposure in rats, following their simultaneous oral co-administration and after a 14-day pre-treatment period with $C$. papaya extract.

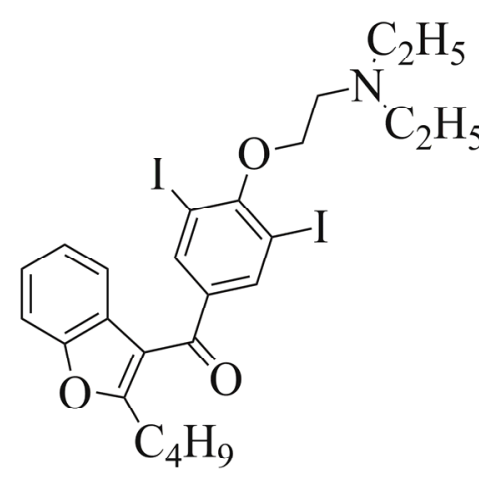

AM

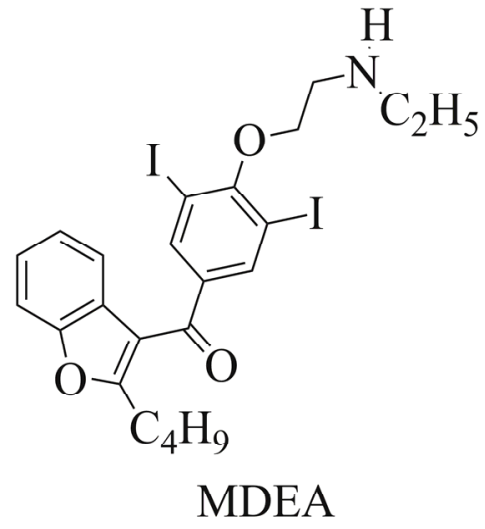

Figure 1. Chemical structures of amiodarone (AM) and its major metabolite mono- $N$-desethylamiodarone (MDEA). 


\section{MATERIALS AND METHODS}

\section{Drugs and materials}

C. papaya extract with a proteolytic activity higher than $6000 \mathrm{NFPU} / \mathrm{mg}$ obtained from papaya fruit was purchased from Bio Serae Laboratories (Bram, France). The certificate of analysis number 420015 - batch 0810960 is provided as Additional file. Carboxymethylcellulose sodium salt used to prepare the extract suspension was obtained from Sigma (St. Louis, MO, USA). A commercial formulation (ampoules) of amiodarone hydrochloride $50 \mathrm{mg} / \mathrm{mL}$ solution for intravenous injection was used for oral administration in rats after appropriate dilution with $5 \%$ glucose intravenous solution for infusion (B. Braun Medical, Portugal). Sodium chloride $0.9 \%$ solution for injection (Labesfal, Portugal), heparin sodium 5000 U.I./mL for injection (B. Braun Medical, Portugal), ketamine for injection (Imalgene 1000) and xylazine for injection (Vetaxilaze 20) were also used. Introcan ${ }^{\circledR}$ Certo IV indwelling cannulas (22G; $0.9 \times 2.5 \mathrm{~mm}$ ) were acquired from B. Braun Melsungen AG (Melsungen, Germany).

\section{Animals}

Adult male Wistar rats $(355 \pm 28$ g) aged approximately 10 weeks were obtained from local animal facilities (Faculty of Health Sciences of the University of Beira Interior, Covilhã, Portugal). The rats were maintained under controlled environmental conditions (temperature $20 \pm 2{ }^{\circ} \mathrm{C}$; relative humidity $55 \pm 5 \%$; 12 -h light/dark cycle). The animals were allowed free access to a standard rodent diet (4RF21, Mucedola, Italy) during almost all experimental procedures and tap water was available ad libitum. At the night of the day before amiodarone administration, a lateral tail vein of each rat was cannulated, under anaesthesia [ketamine (90 $\mathrm{mg} / \mathrm{kg}) / \mathrm{xylazine}(10 \mathrm{mg} / \mathrm{kg})$; i.p. injection], by insertion of an Introcan ${ }^{\circledR}$ Certo IV indwelling cannula (22G; 0.9 x $2.5 \mathrm{~mm}$ ) used for serial blood sampling. The rats fully recovered from anaesthesia overnight and were fasted for 12-14 h before amiodarone administration and maintained with free access to water. In order to avoid the food effect on the oral bioavailability of amiodarone an additional fasting period was considered (4 h post-dose). Oral treatments of the rats with C. papaya extract and amiodarone were performed by gavage. Blood sampling was conducted in conscious and freely moving rats appropriately restrained only at the moment of blood collection; the only exception was at the last blood sampling, which was taken by the terminal procedure (decapitation and exsanguination under anaesthesia). All the animal experiments were conducted in accordance with the European Directive (2010/63/EU) for the accommodation and care of laboratory animals and the experimental procedures were reviewed and approved by the Portuguese Veterinary General Division.

\section{Experimental design and pharmacokinetic studies}

A simultaneous oral co-administration study with a single-dose of $C$. papaya extract and amiodarone, and a 14-day repeated oral pretreatment study with $C$. papaya extract followed by an oral dose of amiodarone on the $15^{\text {th }}$ day were performed to investigate the effects of $C$. papaya fruit extract on the pharmacokinetics of amiodarone. The established dose for amiodarone was $50 \mathrm{mg} / \mathrm{kg}$ since it provides drug plasma concentrations in rats within the amiodarone therapeutic range in humans $(0.5-2 \mu \mathrm{g} / \mathrm{mL})$ $(36,37)$. On the other hand, the dose of $C$. papaya was selected based on the average dose recommended to humans by the supplier of the extract (Bio Serae Laboratories) and taking into account the Food and Drug Administration (FDA) Guidance for Industry on conversion of animal doses to human equivalent doses based on body surface area (38); additionally, a 10-fold potentiating interaction factor was considered in order to avoid potential false-negative results for herb-drug interaction associated to interspecies differences. On each day of the experiments $C$. papaya extract was suspended in $0.5 \%$ carboxymethylcellulose aqueous solution affording a suspension of herbal extract at 123 $\mathrm{mg} / \mathrm{mL}$. Amiodarone commercial injectable solution $(50 \mathrm{mg} / \mathrm{mL})$ was also appropriately diluted with $5 \%$ glucose solution to extemporaneously prepare an amiodarone solution at $12.5 \mathrm{mg} / \mathrm{mL}$. Appropriate volumes of C. papaya extract suspension $(10 \mathrm{~mL} / \mathrm{kg}$ of body weight) and of amiodarone solution ( $4 \mathrm{~mL} / \mathrm{kg}$ of body weight) were orally administered to rats by gavage.

In the first pharmacokinetic study, twelve Wistar rats were randomly divided into two groups (C. papaya and vehicle groups). Rats of the $C$. papaya group $(n=6)$ were concomitantly treated with a single-dose of C. papaya extract $(1230 \mathrm{mg} / \mathrm{kg}$, p.o.) and a single-dose of amiodarone $(50 \mathrm{mg} / \mathrm{kg}$, p.o. $)$; the extract suspension was administered immediately before amiodarone. Rats of the vehicle (control) group ( $n$ 
=6) received, instead of the C. papaya extract suspension, the corresponding volume of $0.5 \%$ carboxymethylcellulose aqueous solution (extract vehicle).

In the second pharmacokinetic study, twelve Wistar rats were also randomly divided into two groups. Rats assigned to the $C$. papaya group ( $n=$ 6) were orally pre-treated with $C$. papaya extract $(1230 \mathrm{mg} / \mathrm{kg}$, p.o.) once a day for 14 consecutive days (short-term repeated dose pre-treatment). Rats allocated to the vehicle (control) group $(n=$ 6) were administered with an equivalent volume of vehicle for the same period of time. During the pre-treatment period, the rats were kept in 12-h light/dark cycle animal room with controlled temperature and humidity, as indicated in Animals section, and free access to a standard rodent diet and tap water was allowed. On the $15^{\text {th }}$ day, the rats of the two groups (C. papaya and vehicle) were gavaged with the single-dose of amiodarone (50 mg/kg, p.o.).

In both pharmacokinetic studies, the treatments with $C$. papaya extract (or vehicle) and/or amiodarone were always carried out in the morning between 9:00 am and 11:45 am. In the night of the day before amiodarone administration, the rats were anaesthetized for cannulation of a lateral tail vein and were fasted overnight as described above (see Animals section). On the following day, multiple serial blood samples (approximately $0.3 \mathrm{~mL}$ per sample) were collected through the cannula into heparinized tubes before dosing and at $0.25,0.5$, $1,2,4,6,8$ and $12 \mathrm{~h}$ following amiodarone administration; at $24 \mathrm{~h}$ post-dose, blood and tissues (heart, liver, kidneys and lungs) were also harvested after decapitation of the rats. The blood samples were centrifuged at $4000 \mathrm{rpm}$ for $10 \mathrm{~min}$ $\left(4{ }^{\circ} \mathrm{C}\right)$ to separate the plasma which was stored at $-20^{\circ} \mathrm{C}$ until analysis. After exsanguinations, liver, kidneys, heart and lungs were excised and stored at $-20{ }^{\circ} \mathrm{C}$; the organs were weighed and homogenized in distilled water $(3 \mathrm{~mL}$ of water per gram of tissue) before analysis of tissue homogenates samples.

\section{Analysis of amiodarone and MDEA}

Plasma and tissue concentrations of amiodarone and its main metabolite MDEA were determined using a liquid-liquid extraction (LLE) procedure followed by high-performance liquid chromatography-diode array detection (HPLCDAD) assay previously developed and validated (39).

Briefly, an aliquot of each plasma sample $(150 \mu \mathrm{L})$ was diluted with $150 \mu \mathrm{L}$ of $0.1 \mathrm{M}$ sodium phosphate buffer $(\mathrm{pH} 5)$ and spiked with $20 \mu \mathrm{L}$ of the internal standard (IS) working solution $(50 \mu \mathrm{g} / \mathrm{mL})$. The mixture was added of $500 \mu \mathrm{L}$ of $n$-hexane (used as LLE solvent), vortex-mixed for $30 \mathrm{sec}$ and centrifuged at 17000 rpm for $2 \mathrm{~min}$ at $4{ }^{\circ} \mathrm{C}$. The upper organic layer was transferred to a clean glass tube and the sample was re-extracted twice more with $n$ hexane $(500 \mu \mathrm{L}$ each time) using the same experimental conditions. Then, the whole organic extract was evaporated to dryness under a nitrogen stream at $60{ }^{\circ} \mathrm{C}$ and the residue was reconstituted in methanol $(100 \mu \mathrm{L})$. Following this, an aliquot of the reconstituted extract $(20 \mu \mathrm{L})$ was injected into the HPLC system for analysis. On the other hand, for the analysis of tissues, each aliquot $(400 \mu \mathrm{L})$ of tissue (heart, liver, kidney and lung) homogenates was spiked with $20 \mu \mathrm{L}$ of the IS working solution $(50 \mu \mathrm{g} / \mathrm{mL})$; then, the mixture was added of $400 \mu \mathrm{L}$ of acetonitrile (used as protein precipitating agent), vortex-mixed for 1 min and centrifuged at $17000 \mathrm{rpm}$ for $10 \mathrm{~min}$ at 4 ${ }^{\circ} \mathrm{C}$ in order to precipitate the protein content. The supernatant was transferred to a new tube and 1 $\mathrm{mL}$ of $n$-hexane (used as LLE solvent) was added. The mixture was vortex-mixed for $1 \mathrm{~min}$ and centrifuged at $17000 \mathrm{rpm}$ for $5 \mathrm{~min}$ at $4{ }^{\circ} \mathrm{C}$. The upper organic layer ( $n$-hexane) was transferred to a clean glass tube and the sample was re-extracted twice more with $n$-hexane $(0.8 \mathrm{~mL}$ each time) using the same conditions. The organic extract was evaporated to dryness, reconstituted, and then injected into the HPLC system using the same procedures as mentioned above for rat plasma samples.

The chromatographic separation of amiodarone, MDEA and IS was achieved within less than $5 \mathrm{~min}$ on a reversed-phase LiChroCART Purospher Star C18 column [55 $\mathrm{mm} \times 4 \mathrm{~mm} ; 3$ $\mu \mathrm{m}$; Merck KGaA (Darmstadt, Germany)] by elution with a mobile phase consisting of phosphate buffer $(50 \mathrm{mM})$ with $0.1 \%$ formic acid $(\mathrm{pH}$ 3.1)-methanol-acetonitrile $(45: 5: 50, \mathrm{v} / \mathrm{v} / \mathrm{v})$ pumped at a flow rate of $1.2 \mathrm{~mL} / \mathrm{min}$. The detection was conducted at $254 \mathrm{~nm}$ for all compounds. Calibration curves were linear $\left(r^{2} \geq\right.$ $0.995)$ in the range of $0.10-15 \mu \mathrm{g} / \mathrm{mL}$ for amiodarone and MDEA. The limit of quantification was established at $0.10 \mu \mathrm{g} / \mathrm{mL}$ for each of the analytes (amiodarone and MDEA) in both plasma and tissue homogenates, with acceptable precision $(\mathrm{CV} \leq 11.5 \%)$ and accuracy (bias $\pm 12.8 \%$ ). The overall intra- and inter-day imprecision (\% CV) did not exceed $6.56 \%$ and the inaccuracy ( $\%$ bias $)$ was within $\pm 7.9 \%$. The mean recoveries for amiodarone and MDEA ranged 
from 59.9 to $97.6 \%$. The analysis of all blank rat matrices (plasma and heart, liver, kidney and lung tissue homogenates) showed no endogenous interferences at the retention times of IS, MDEA and amiodarone. Likewise, interferences from exogenous compounds such as ketamine, xylazine and heparin and C. papaya extract were not found at the retention times of the chromatographic peaks of IS, MDEA and amiodarone.

\section{Pharmacokinetic analysis}

The plasma concentration versus time data for amiodarone and MDEA obtained from each individual rat were submitted to a noncompartmental pharmacokinetic analysis using the WinNonlin ${ }^{\circledR}$ version 4.1 (Pharsight Co, Mountain View, CA, USA). The peak plasma concentrations $\left(\mathrm{C}_{\max }\right)$ of amiodarone and MDEA and the time to reach $\mathrm{C}_{\max }\left(\mathrm{t}_{\max }\right)$ were obtained directly from the experimental data. Other pharmacokinetic parameters estimated from the individual plasma concentration-time profiles included: area under the concentration-time curve (AUC) from time zero to the last sampling time at which concentrations were at or above the limit of quantification (LOQ; $0.10 \mu \mathrm{g} / \mathrm{mL}$ ) of the method $\left(\mathrm{AUC}_{0-\mathrm{t}}\right)$, calculated by the linear trapezoidal rule; AUC from time zero to infinite $\left(\mathrm{AUC}_{0-\infty}\right)$, calculated from $\mathrm{AUC}_{0-\mathrm{t}}+\left(\mathrm{C}_{\text {last }} / \mathrm{k}_{\mathrm{el}}\right)$, where $\mathrm{C}_{\text {last }}$ is the last quantifiable concentration and $\mathrm{k}_{\mathrm{el}}$ is the apparent terminal elimination rate constant calculated by log-linear regression of the terminal segment of the concentration-time profile; apparent terminal elimination half-life $\left(\mathrm{t}_{1 / 2 \mathrm{el}}\right)$ and mean residence time (MRT). The concentrations lower than the LOQ of the assay were taken as zero for all calculations.

\section{Short-term repeated dose effect of $C$. papaya extract on body weight}

In the short-term $C$. papaya repeated dose study the body weight of the rats treated with $C$. papaya extract $(1230 \mathrm{mg} / \mathrm{kg} /$ day, p.o.; experimental group) or vehicle (control group) was adequately registered on the first day and also on the last day of these treatments $\left(14^{\text {th }}\right)$ in order to investigate the effect of the herbal extract on body weight changes.

\section{STATISTICAL ANALYSIS}

Data were reported as the mean \pm standard error of the mean (SEM). Comparisons between two groups were usually performed using unpaired two-tailed Student's $t$-test; for body weight comparisons within the same group the paired
Student's $t$-test was applied. The differences were considered to be statistically significant for a $p$ value lower than $0.05(p<0.05)$.

\section{RESULTS}

\section{Simultaneous co-administration of $C$. papaya and amiodarone}

The mean plasma concentration-time profiles $(n=$ 6) of amiodarone and its main metabolite (MDEA) obtained after the co-administration of rats with a single-dose of $C$. papaya extract (1230 $\mathrm{mg} / \mathrm{kg}$, p.o.) or vehicle (control group) and a single-dose of amiodarone $(50 \mathrm{mg} / \mathrm{kg}$, p.o.) are shown in Figure 2. Up to $24 \mathrm{~h}$ post-dosing no statistically significant differences $(p>0.05)$ were found between the two groups of rats (C. papaya versus vehicle) regarding the mean plasma concentrations of amiodarone achieved at each sampling time points. Plasma concentrations of MDEA were similar in the two groups, showing concentration values near or below the LOQ $(0.10$ $\mu \mathrm{g} / \mathrm{mL}$ ), which were manifestly lower than those obtained for amiodarone. The main pharmacokinetic parameters estimated for amiodarone and MDEA after a noncompartmental analysis of their individual plasma concentration-time profiles are summarized in Table 1. Considering the paucity of quantifiable plasma concentrations obtained for MDEA, it was only possible to present the $\mathrm{C}_{\max }$ and $\mathrm{t}_{\max }$ parameters (Table 1). Overall, the $\mathrm{C}_{\max }$ of amiodarone was attained later in the group treated with $C$. papaya comparatively to the vehicle (control) group. However, no statistically significant differences were found for the mean pharmacokinetic parameters in terms of extent of systemic exposure of amiodarone and its main metabolite (MDEA) among the two groups (Table 1).

To evaluate the distribution of amiodarone and MDEA after its co-administration with the $C$. papaya extract, the animals were sacrificed at 24 $\mathrm{h}$ post-dosing and several tissues were excised and analysed. The mean concentrations of amiodarone and MDEA in heart, lung, liver and kidney tissues, and also in plasma at the same time point ( $24 \mathrm{~h}$ post-dose) are shown in Figure 3. The tissue concentrations of amiodarone and MDEA were markedly higher than those determined in plasma. However, taking into account the comparisons performed between the C. papaya and the vehicle (control) groups, statistically significant differences were only detected for amiodarone concentrations in kidney tissue $(p<0.05)$, being significantly higher in the 
kidney tissue of rats treated with the herbal extract.

\section{Short-term repeated dose pre-treatment with $C$. papaya followed by administration of amiodarone}

Rats were administered for 14 days with $C$. papaya extract $(1230 \mathrm{mg} / \mathrm{kg}$, p.o.) or vehicle (control group) in order to investigate the influence of a short-term repeated dose pretreatment with $C$. papaya extract on the pharmacokinetics of amiodarone, which was only administered on the $15^{\text {th }}$ day as a single-dose of $50 \mathrm{mg} / \mathrm{kg}$ (p.o.). The mean plasma concentrationtime profiles $(n=6)$ of amiodarone and its main metabolite (MDEA) are depicted in Figure 4.
Comparing the mean plasma concentrations of amiodarone in the two groups, there are statistically significant differences at 6,8 and $24 \mathrm{~h}$ post-dosing $(p<0.05)$ and the concentrations were higher in the group pre-treated with $C$. papaya extract. The corresponding pharmacokinetic parameters are listed in Table 2. The $C$. papaya extract pre-treatment of the rats showed a statistically significant increase in the extent of systemic exposure to amiodarone (as assessed by $\mathrm{AUC}_{0-\mathrm{t}}$ and $\left.\mathrm{AUC}_{0-\infty}\right)$. In the C. papaya group a considerable delay in reaching $\mathrm{C}_{\max }$ of amiodarone was also observed. The plasma concentrations of MDEA were near or below the LOQ $(0.10 \mu \mathrm{g} / \mathrm{mL})$ of the method in the two groups of rats.

\begin{tabular}{|c|c|c|c|c|}
\hline \multirow{2}{*}{ Parameter } & \multicolumn{2}{|c|}{ AM Carica } & \multicolumn{2}{|c|}{ AM Vehicle } \\
\hline & AM & MDEA & AM & MDEA \\
\hline $\mathrm{t}_{\max }(\mathrm{h})$ & $2.5 \pm 0.5$ & $6.0 \pm 0.0^{\mathrm{a}}$ & $1.8 \pm 0.5$ & $7.2 \pm 1.4^{\mathrm{b}}$ \\
\hline $\mathrm{C}_{\max }(\mu \mathrm{g} / \mathrm{mL})$ & $1.53 \pm 0.41$ & $0.13 \pm 0.02^{\mathrm{a}}$ & $1.378 \pm 0.179$ & $0.125 \pm 0.012^{\mathrm{b}}$ \\
\hline $\mathrm{AUC}_{0-\mathrm{t}}(\mu \mathrm{g} \cdot \mathrm{h} / \mathrm{mL})$ & $15.59 \pm 3.41$ & ND & $12.77 \pm 0.69$ & ND \\
\hline $\operatorname{AUC}_{0-\infty}(\mu \mathrm{g} . \mathrm{h} / \mathrm{mL})$ & $25.69 \pm 3.49$ & ND & $21.43 \pm 2.08$ & ND \\
\hline $\mathrm{k}_{\mathrm{el}}(1 / \mathrm{h})$ & $0.0470 \pm 0.0102$ & ND & $0.0433 \pm 0.0082$ & ND \\
\hline$t_{1 / 2 \mathrm{el}}(\mathrm{h})$ & $19.9 \pm 5.3$ & ND & $20.7 \pm 5.7$ & ND \\
\hline MRT (h) & $29.8 \pm 8.0$ & ND & $28.6 \pm 7.7$ & ND \\
\hline
\end{tabular}

\section{Co-administration (Carica versus Vehicle)}

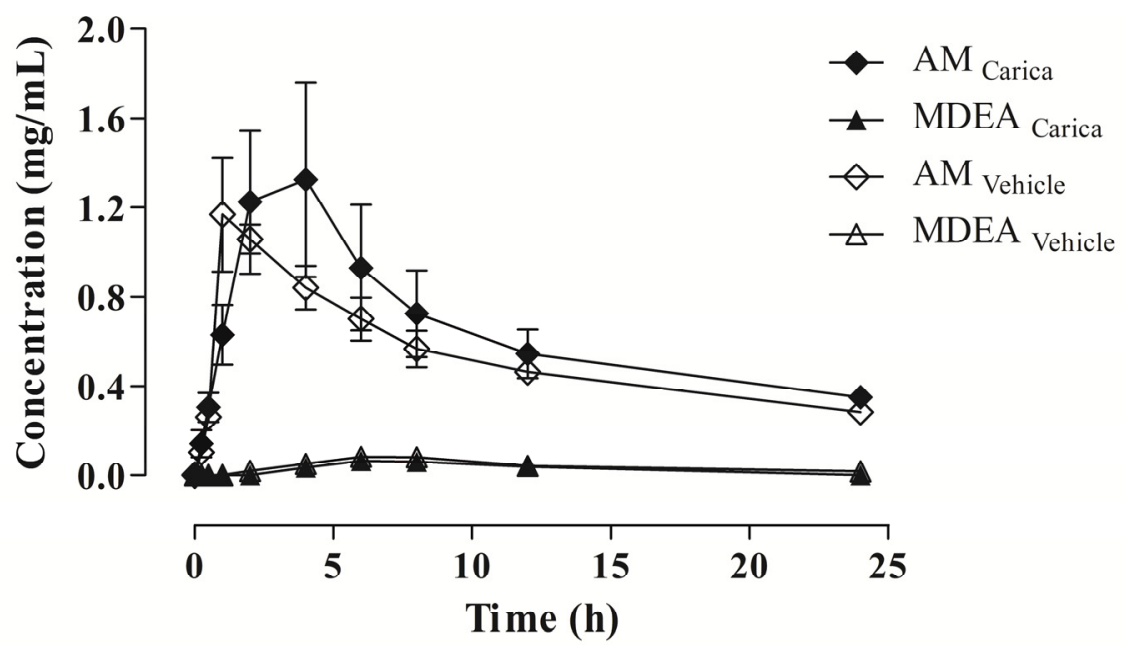

Figure 2. Mean plasma concentration-time profiles of amiodarone (AM) and mono- $N$-desethylamiodarone (MDEA) obtained, over a period of $24 \mathrm{~h}$, from rats simultaneously treated with a single-dose of Carica papaya extract (1230 $\mathrm{mg} / \mathrm{kg}$, p.o.), or vehicle ( $0.5 \%$ carboxymethylcellulose aqueous solution), and AM (50 mg/kg, p.o.) by oral gavage. Symbols represent the mean values \pm standard error of the mean (SEM) of six determinations per time point $(n=6)$. 


\section{Co-administration (Carica versus Vehicle)}

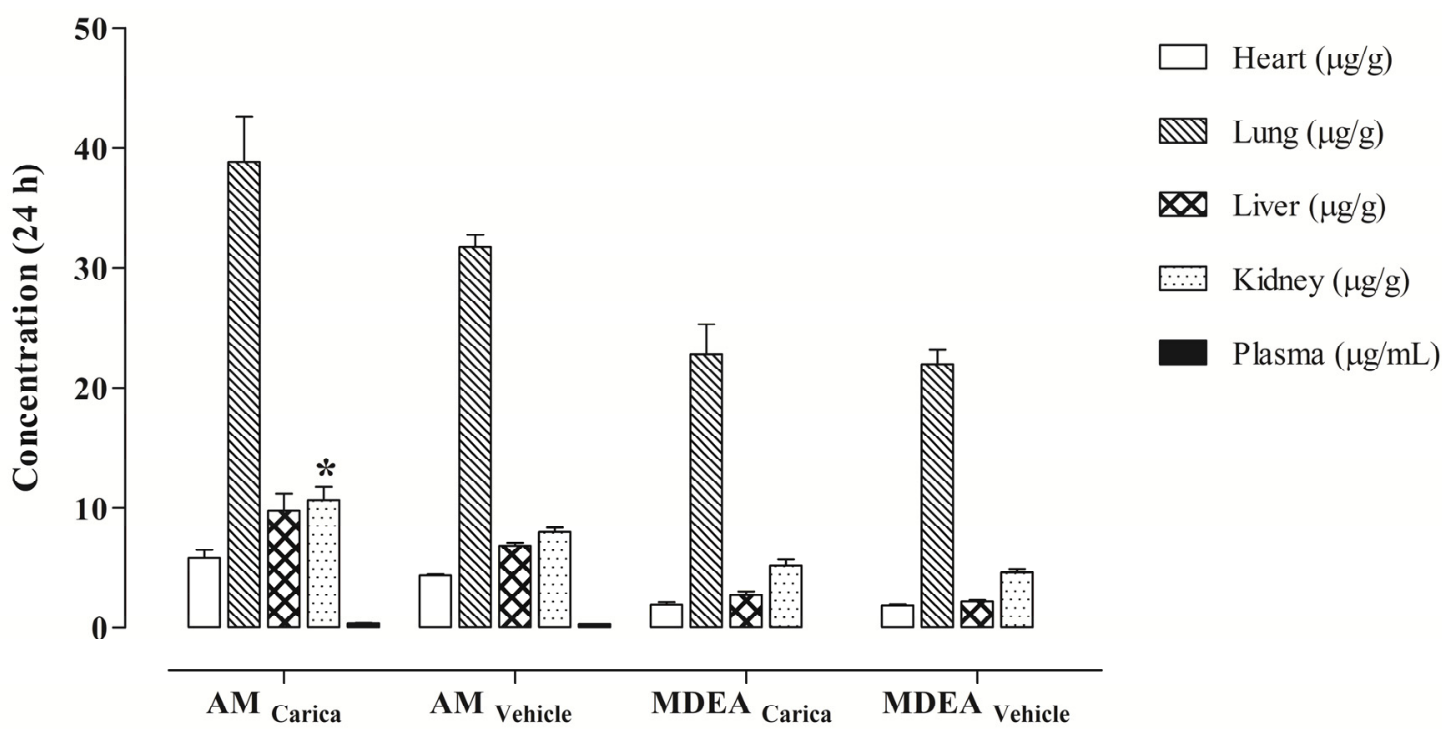

Figure 3. Mean plasma and tissue (heart, lung, liver and kidney) concentrations of amiodarone (AM) and mono- $N$ desethylamiodarone (MDEA) obtained, at $24 \mathrm{~h}$ post-dose, from rats simultaneously treated with a single-dose of Carica papaya extract $(1230 \mathrm{mg} / \mathrm{kg}$, p.o.), or vehicle (0.5\% carboxymethylcellulose aqueous solution), and $\mathrm{AM}(50 \mathrm{mg} / \mathrm{kg}$, p.o.) by oral gavage. Data are expressed as the mean values \pm standard error of the mean (SEM) of six determinations $(n=6) .{ }^{*} p<0.05$ compared to control (vehicle).

To assess the impact of a 14-day pretreatment period with $C$. papaya extract on the distribution and metabolism of amiodarone in rats, the concentrations of amiodarone and its major metabolite (MDEA) were also determined in various tissues (additionally to plasma) at $24 \mathrm{~h}$ post-dose and the data are shown in Figure 5. Once again, the tissue concentrations of both compounds (amiodarone and MDEA) were distinctly higher than those measured in plasma. However, despite the statistically significant differences detected in the plasma concentrations of amiodarone at 6,8 and $24 \mathrm{~h}$ post-dose between the two groups (Figure 4), statistically significant differences in the mean tissue concentrations of amiodarone were only found in the lung tissue, while MDEA concentrations obtained from rats pre-treated with $C$. papaya extract were higher in lung and heart tissues.

\section{Short-term repeated dose effect of $C$. papaya extract on body weight}

In the rats submitted to a 14-day pre-treatment period with C. papaya extract $(1230 \mathrm{mg} / \mathrm{kg} /$ day, p.o) or vehicle a statistically significant increase was found in the body weight of the two groups. In the group of rats treated with C. papaya extract was observed an increase in the body weight from
$368.0 \pm 12.6 \mathrm{~g}$ to $382.3 \pm 15.4 \mathrm{~g}(\mathrm{p}<0.01)$ and in the group treated with vehicle the body weight increased from $341.0 \pm 7.6 \mathrm{~g}$ to $362.2 \pm 8.8 \mathrm{~g}(\mathrm{p}<$ $0.001)$. Furthermore, the increase in the body weight was comparable $(14.3 \pm 3.5 \mathrm{~g}$ vs. $21.2 \pm$ $2.2 \mathrm{~g}, \mathrm{p}>0.05)$ between the two groups of rats $(C$. papaya versus vehicle). Hence, under these experimental conditions, the $C$. papaya extract was shown to be ineffective to control the body weight gain in rats.

\section{DISCUSSION}

Most of the herb-drug interaction studies found in literature have been conducted in vitro conditions employing concentrations usually higher than the clinically relevant ones (17) and, up to date, few significant drug interactions have actually been accurately predicted from in vitro assays (40). Thus, taking into account these limitations, the present work evaluated the potential of interaction between $C$. papaya extract and amiodarone in a whole animal model, the Wistar rat.

Overall, our results showed that the singledose co-administration of $C$. papaya extract and amiodarone caused a delay in the $t_{\max }$, but did not alter the extent of systemic exposure to amiodarone (as assessed by $\mathrm{AUC}_{0-\mathrm{t}}$ and $\mathrm{AUC}_{0-\infty}$ ). 
Table 2 - Pharmacokinetic parameters estimated by non-compartmental analysis of the plasma concentration-time profiles of amiodarone (AM) and mono- $N$-desethylamiodarone (MDEA, major metabolite of AM) obtained in rats submitted to a 14-day pre-treatment period with Carica papaya extract $(1230 \mathrm{mg} / \mathrm{kg} /$ day, p.o.), or vehicle $(0.5 \%$ carboxymethylcellulose aqueous solution), and treated on the $15^{\text {th }}$ day with a single-dose of AM $(50 \mathrm{mg} / \mathrm{kg}$, p.o.) by oral gavage $(n=6$, unless otherwise noted).

\begin{tabular}{|c|c|c|c|c|}
\hline \multirow[t]{2}{*}{ Parameter } & \multicolumn{2}{|c|}{ AM $M_{\text {Carica }}$} & \multicolumn{2}{|c|}{$\mathrm{AM}_{\text {Vehicle }}$} \\
\hline & AM & MDEA & $\mathrm{AM}$ & MDEA \\
\hline $\mathrm{t}_{\max }(\mathrm{h})$ & $3.2 \pm 0.5$ & $10.5 \pm 2.1^{\mathrm{a}}$ & $2.2 \pm 0.6$ & $7.3 \pm 2.4^{b}$ \\
\hline $\mathrm{C}_{\max }(\mu \mathrm{g} / \mathrm{mL})$ & $1.44 \pm 0.22$ & $0.14 \pm 0.01^{\mathrm{a}}$ & $0.95 \pm 0.16$ & $0.12 \pm 0.01^{b}$ \\
\hline $\mathrm{AUC}_{0-\mathrm{t}}(\mu \mathrm{g} \cdot \mathrm{h} / \mathrm{mL})$ & $16.93 \pm 2.56^{*}$ & ND & $10.53 \pm 0.89$ & ND \\
\hline $\operatorname{AUC}_{0-\infty}(\mu \mathrm{g} . \mathrm{h} / \mathrm{mL})$ & $26.64 \pm 2.53^{\#}$ & ND & $15.33 \pm 0.95$ & ND \\
\hline $\mathrm{K}_{\mathrm{el}}(1 / \mathrm{h})$ & $0.0541 \pm 0.0127$ & ND & $0.0533 \pm 0.0082$ & ND \\
\hline $\mathrm{t}_{1 / 2 \mathrm{el}}(\mathrm{h})$ & $18.3 \pm 5.1$ & ND & $14.4 \pm 1.9$ & ND \\
\hline $\operatorname{MRT}(\mathrm{h})$ & $27.1 \pm 7.1$ & ND & $21.0 \pm 2.4$ & ND \\
\hline
\end{tabular}

ND, not determined.

${ }^{\mathrm{a}} \mathrm{n}=4 ;{ }^{\mathrm{b}} \mathrm{n}=3$.

${ }^{*} p<0.05$, significantly different from the control group.

${ }^{\#} p<0.005$, significantly different from the control group.

\section{Pre-treatment (Carica versus Vehicle)}

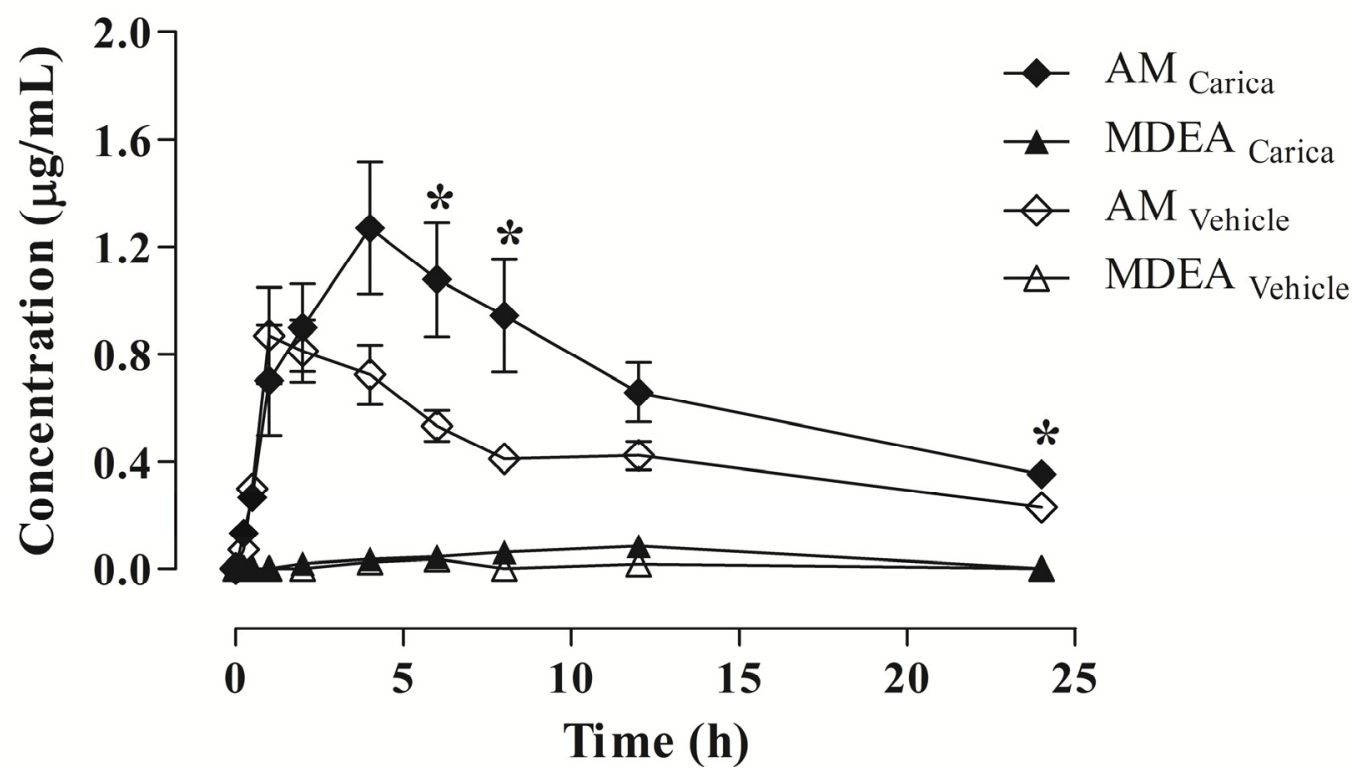

Figure 4. Mean plasma concentration-time profiles of amiodarone (AM) and mono- $N$-desethylamiodarone (MDEA) obtained, over a period of $24 \mathrm{~h}$, from rats submitted to a 14-day pre-treatment period with Carica papaya extract (1230 $\mathrm{mg} / \mathrm{kg} /$ day, p.o.), or vehicle $(0.5 \%$ carboxymethylcellulose aqueous solution $)$, and treated on the $15^{\text {th }}$ day with a singledose of AM $(50 \mathrm{mg} / \mathrm{kg}$, p.o.) by oral gavage $(n=6)$. Symbols represent the mean values \pm standard error of the mean $(\mathrm{SEM})$ of six determinations per time point $(n=6) .{ }^{*} p<0.05$ compared to control (vehicle).

This delay in $t_{\max }$ is not expected to change the efficacy of amiodarone and it is unlikely to be clinically important. It is interesting to emphasise that after the co-administration of amiodarone with other herbal extracts that are claimed to be useful in weight loss/weight management (e.g. Citrus aurantium extract, Fucus vesiculosus extract and Paullinia cupana extract) a delay in the time to reach $\mathrm{C}_{\max }$ was also observed; however, the co-administration with Fucus vesiculosus extract or Paullinia cupana extract also significantly decreased the systemic exposure to amiodarone in the rats (41-43).

Moreover, because of the central role that the induction of cytochrome P450 (CYP) isoenzymes and P-glycoprotein (P-gp) play on drug-drug and herb-drug interactions, and bearing in mind that the induction mechanisms are time-dependent, the 
interference of $C$. papaya extract on the pharmacokinetics of amiodarone was also evaluated by administering the herbal extract for 14 consecutive days until $24 \mathrm{~h}$ before administering a single-dose of the drug. In the rats pre-treated with $C$. papaya extract during the 14 days, a statistically significant increase in the extent of systemic drug exposure was observed comparatively with control group (as assessed by $\mathrm{AUC}_{0-\mathrm{t}}$ and $\left.\mathrm{AUC}_{0-\infty}\right)$. However, no significant differences were found in the peak of systemic exposure to amiodarone (as assessed by $\mathrm{C}_{\max }$ ). Thus, to explain the higher systemic exposure to amiodarone in the $C$. papaya group we hypothesize that the herbal extract or some of its phytochemical constituents could have antimotility properties, determining the inhibition of the intestinal propulsion movements (11). The reduction of gastrointestinal motility can prolong the transit time of drugs and, consequently, can increase the extent of absorption of slightly soluble drugs, such as the amiodarone (44). In fact, the low aqueous solubility of amiodarone is the rate-limiting step of its intestinal absorption, which occurs by passive diffusion (a nonsaturable transport process) $(45,46)$.

Another possibility to explain the higher $\mathrm{AUC}_{0-\mathrm{t}}$ and $\mathrm{AUC}_{0-\infty}$ values found for amiodarone in the group of rats pre-treated with $C$. papaya extract could be related to a time-dependent inhibitory effect on CYP isoenzymes and/or P-gpmediated efflux activity. Theoretically, a drug that is a dual substrate for CYPs and P-gp has a much higher potential for drug interactions with herbs that also modulate CYP3A4 and P-gp (24). In fact, amiodarone is metabolized by several CYP isoenzymes including CYP1A1/2, CYP2C8, CYP2C19, CYP2D6 and CYP3A4 $(27,47)$ and it is also a substrate of P-gp $(48,49)$. In addition, there is some evidence regarding the effects of $C$. papaya on CYPs and/or P-gp activity; the fruit of $C$. papaya seems to produce inhibitory effects on the activity of CYP3A and CYP2E1 in human and mouse liver microsomes, respectively $(50,51)$. The juice of $C$. papaya has also shown a weak inhibitory effect on the CYP2C9 activity in human liver microsomes (52). Oga et al. (53) also reported the inhibition of P-gp in Caco-2 cells mediated by the leaf extract of $C$. papaya. In addition, the aqueous extract of $C$. papaya leaves significantly increased $(54.5 \%)$ the apparent permeability of the P-gp substrate digoxin in the mucosal-to-serosal direction in intestinal segments mounted in Ussing chambers (54). However, the co-administration of the leaf extract of $C$. papaya and digoxin in rats did not determine a significant increase in the extent of systemic drug exposure (54).

\section{Pre-treatment (Carica versus Vehicle)}

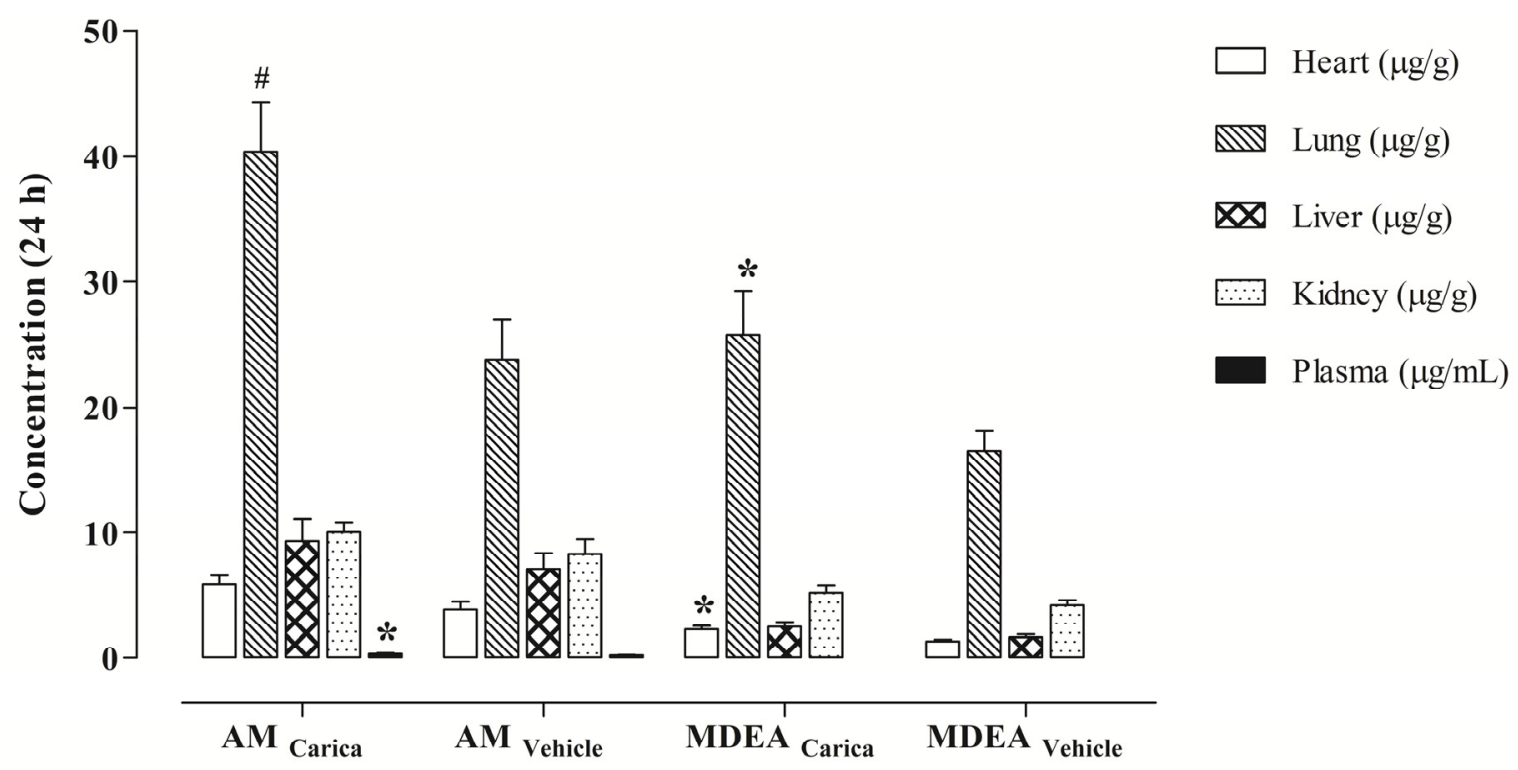

Figure 5. Mean plasma and tissue (heart, lung, liver and kidney) concentrations of amiodarone (AM) and mono- $N$ desethylamiodarone (MDEA) obtained, at $24 \mathrm{~h}$ post-dose, from rats submitted to a 14-day pre-treatment period with Carica papaya extract $(1230 \mathrm{mg} / \mathrm{kg} / \mathrm{day}, \mathrm{p} . \mathrm{o}$.$) , or vehicle (0.5 \%$ carboxymethylcellulose aqueous solution $)$, and treated on the $15^{\text {th }}$ day with a single-dose of AM $(50 \mathrm{mg} / \mathrm{kg}$, p.o.) by oral gavage. Data are expressed as the mean values \pm standard error of the mean (SEM) of six determinations $(n=6)$. $* p<0.05$ and ${ }^{\#} p<0.01$ compared to control (vehicle). 
Regarding the tissue distribution data obtained at $24 \mathrm{~h}$ post-dose, only deserves to be highlighted the higher concentration levels of amiodarone found in lungs and the greater exposure of heart and lung tissues to MDEA in the group pre-treated with $C$. papaya extract. Therefore, the repeated administration of $C$. papaya extract could contribute to the tissue accumulation and, consequently, to the target organ toxicity ascribed to amiodarone and MDEA.

Based on the herb-drug interaction data between $C$. papaya extract and amiodarone found in the present work, it is suggested that this herbal extract influences the pharmacokinetics of amiodarone, particularly after the repeated treatment; indeed, the 14-day pre-treatment period with $C$. papaya induced an increase in the bioavailability of amiodarone. Even so, it should be taken in account that results from animal experiments cannot be directly extrapolated to humans; however, bearing in mind the studies of Meng et al. (55) and Shayeganpour et al. (36), the rat appears to be an appropriate model for man in this case. Indeed, the mean peak plasma concentrations of amiodarone achieved in our work $\left(\mathrm{C}_{\max } 1.38 \mu \mathrm{g} / \mathrm{mL}\right.$ and $\left.0.95 \mu \mathrm{g} / \mathrm{mL}\right)$ are within the established drug therapeutic range (0.5$2 \mu \mathrm{g} / \mathrm{mL})(36,37)$ and such concentrations were only slightly higher than the levels found in other studies performed in Wistar rats with same dosage $(50 \mathrm{mg} / \mathrm{kg})$ of amiodarone $\left(\mathrm{C}_{\max } 0.78 \mu \mathrm{g} / \mathrm{mL}\right.$ and $0.84 \mu \mathrm{g} / \mathrm{mL})(56)$.

Additionally, in the present study, the increase of body weight of the rats pre-treated during 14 days with $C$. papaya extract or vehicle was comparable. Despite there is evidence in literature that $C$. papaya has anti-obesity effects, our data do not support these findings. In a study conducted by Athesh et al. (9) in which rats fed with high fat diet were treated during a 14-day period with $C$. papaya extract at doses in the range of $200-600 \mathrm{mg} / \mathrm{kg}$ only a slight reduction in body weight gain was observed. Indeed, the antiobesity effect was more evident after 45 days of treatment with $C$. papaya fruit extract. In other studies the treatment with $C$. papaya seed extract induced a reduction in body weight gain of rats when doses of 100 to $400 \mathrm{mg} / \mathrm{kg}$ were administered over 30 days and doses of 2000 $\mathrm{mg} / \mathrm{kg}$ were administered during 14 days (12); moreover, a 28-day treatment period with 5 to $20 \%$ of ground bark extract of C. papaya in the diet also determined a reduction in body weight gain of rats comparatively to the control group (57). At last, in a study conducted by Goyal et al.
(58) no significant changes were observed in the body weight of the rats treated during 52 days with doses of 50 to $500 \mathrm{mg} / \mathrm{kg}$ of the methanol sub-fraction of $C$. papaya seeds.

\section{CONCLUSION}

In conclusion, the single-dose co-administration of C. papaya fruit extract and amiodarone had no major effects on the pharmacokinetics of amiodarone in rats; at this point, only the delay induced by herbal extract in reaching the peak plasma concentration of amiodarone should be highlighted. On the other hand, following a 14day pre-treatment period with $C$. papaya extract marked changes were found in the systemic exposure to amiodarone. Apart from a slight delay in achieving the $\mathrm{C}_{\max }$, the significant increase observed in the extent of amiodarone systemic exposure in the group of rats treated with $C$. papaya was noteworthy. Hence, the repeated administration of $C$. papaya extract may clearly affect the bioavailability of amiodarone. Nevertheless, it is important to be aware that this work only provides a non-clinical proof of the effects of $C$. papaya extract on the pharmacokinetics of amiodarone and, thus, further clinical studies should be performed aiming at confirming this herb-drug interaction in humans.

\section{ACKNOWLEDGMENTS}

This work was supported by Fundação para a Ciência e a Tecnologia (FCT, Portugal) through the fellowships (SFRH/BD/61901/2009) and (SFRH/BPD/46826/2008), involving the POPH (Programa Operacional Potencial Humano), which is co-funded by FSE (Fundo Social Europeu), União Europeia. The authors also wish to acknowledge the fellowship of Joana Francisco supported by the Programa Operacional Regional do Centro 2007-2013 QREN (Programa "Mais Centro”. CENTRO-07-ST24-FEDER-002014).

\section{ABBREVIATIONS}

AM, amiodarone; AUC, area under the concentration-time curve; $\mathbf{A U C}_{\mathbf{0}-\mathrm{t}}$, $\mathrm{AUC}$ from time zero to the last sampling time; $\mathbf{A U} \mathbf{C}_{\mathbf{0}-\infty}, \mathrm{AUC}$ from time zero to infinite; $\mathbf{C}_{\text {last }}$, last quantifiable concentration; $\mathbf{C}_{\max }$, peak plasma concentration; CYP, cytochrome P450; FDA, Food and Drug Administration; HPLC-DAD, high-performance liquid chromatography-diode array detection; INR, international normalized ratio; i.p., intraperitoneal; IS, internal standard; $\mathbf{k}_{\mathrm{el}}$, apparent 
terminal elimination rate constant; LLE, liquidliquid extraction; LOQ, limit of quantification; MDEA, mono- $N$-desethylamiodarone; MRT, mean residence time; P-gp, P-glycoprotein; p.o., per os; SEM, standard error of the mean; $\mathbf{t}_{1 / 2 \mathrm{el}}$, apparent terminal elimination half-life; $\mathbf{t}_{\mathbf{m a x}}$, time to reach $\mathrm{C}_{\max }$.

\section{REFERENCES}

1. Canini A, Alesiani D, D'Arcangelo G, Tagliatesta P. Gas chromatography-mass spectrometry analysis of phenolic compounds from Carica papaya L. leaf. J Food Compost Anal, 1980; 20:584-590.

2. Sadek KM. Antioxidant and immunostimulant effect of Carica papaya linn. aqueous extract in acrylamide intoxicated rats. Acta Inform Med, 2012; 20:180-185.

3. Afzan A, Abdullah NR, Halim SZ, Rashid BA, Semail RHR, Abdullah N, Jantan I, Muhammad H, Ismail Z. Repeated dose 28-days oral toxicity study of Carica papaya L. leaf extract in Sprague Dawley rats. Molecules, 2012; 17:4326-4343.

4. Anuar NS, Zahari SS, Taib, IA, Rahman MT. Effect of green and ripe Carica papaya epicarp extracts on wound healing and during pregnancy. Food Chem Toxicol, 2008; 46:2384-2389.

5. Krishna KL, Paridhavi M, Patel JA. Review on nutritional, medicinal and pharmacological properties of Papaya (Carica papaya Linn.). NPR, 2008; 7:364-373.

6. Aravind G, Debjit B, Duraivel S, Harish G. Traditional and medicinal uses of Carica papaya. Journal of Medicinal Plants Studies, 2008; 1:7-15.

7. Nguyen TT, Shaw PN, Parat MO, Hewavitharana AK. Anticancer activity of Carica papaya: a review. Mol Nutr Food Res, 2013; 57:153-164.

8. Milind P, Gurditta: Basketful benefits of papaya. IRJP, 2011; 2:6-12.

9. Athesh K, Karthiga D, Brindha P. Anti-obesity effect of aqueous extract of Carica papaya $\mathrm{L}$. in rats fed on high fat cafeteria diet. Int J Pharm Pharm Sci, 2012; 4 (Suppl 3):327-330.

10. Kovendan K, Murugan K, Panneerselvam C, Aarthi N, Kumar PM, Subramaniam J, Amerasan D, Vincent S. Antimalarial activity of Carica papaya (family: Caricaceae) leaf extract against Plasmodium falciparum. Asian Pac J Trop Dis, 2012; 2 (Suppl 1):S306-S311.

11. Ezike AC, Akah PA, Okoli CO, Ezeuchenne NA, Ezeugwu S. Carica papaya (Paw-Paw) unripe fruit may be beneficial in ulcer. J Med Food, 2009; 12:1268-1273.

12. Adeneye AA, Olagunju JA. Preliminary hypoglycemic and hypolipidemic activities of the aqueous seed extract of Carica papaya Linn. in Wistar rats. Biology and Medicine, 2009; 1:1-10.

13. Iver D, Sharma BK, Patil UK. Effect of ether- and water-soluble fractions of Carica papaya ethanol extract in experimentally induced hyperlipidemia in rats. Pharm Biol, 2011; 49:1306-1310.

14. Izzo AA: Herb-drug interactions: an overview of the clinical evidence. Fundam Clin Pharmacol, 2004; 19:1-16.

15. Calixto JB. Efficacy, safety, quality control, marketing and regulatory guidelines for herbal medicines (phytotherapeutic agents). Braz J Med Biol Res, 2000; 33:179-189.

16. Bent S. Herbal medicine in the United States: review of efficacy, safety, and regulation: grand rounds at University of California, San Francisco Medical Center. J Gen Intern Med, 2008; 23:854859.

17. Venkataramanan R, Komoroski B, Strom S. In vitro and in vivo assessment of herb drug interactions. Life Sci, 2006; 78:2105-2115.

18. Shaw D, Leon C, Kolev S, Murray V. Traditional remedies and Food Supplements a 5-year toxicological study (1991-1995). Drug Saf, 1997; 17:342-356.

19. Nutescu EA, Shapiro LN, Ibrahim S, West P. Warfarin and its interactions with foods, herbs and other dietary supplements. Expert Opin Drug Saf, 2006; 5:433-451.

20. Pittler MH, Schmidt K, Ernst E. Adverse events of herbal food supplements for body weight reduction: systematic review. Obes Rev, 2005; 6:93-111.

21. Scaglione R, Argano C, Di Chiara T, Licata G. Obesity and cardiovascular risk: the new public health problem of worldwide proportions. Expert Rev Cardiovasc Ther, 2004; 2:203-212.

22. Bodary PF, Iglay HB, Eitzman DT. Strategies to reduce vascular risk associated with obesity. Curr Vasc Pharmacol, 2007; 5:249-258.

23. Zalesin KC, Franklin BA, Miller WM, Peterson $\mathrm{ED}$, McCullough PA. Impact of obesity on cardiovascular disease. Med Clin North Am 2011, 95:919-937.

24. Zhou SF, Zhou ZW, Li CG, Chen X, Yu X, Xue $\mathrm{CC}$, Herington A. Identification of drugs that interact with herbs in drug development. Drug Discov Today 2007, 12:664-673.

25. Butterweck V, Derendorf H. Potential of pharmacokinetic profiling for detecting herbal interactions with drugs. Clin Pharmacokinet 2008, 47:383-397.

26. Papiris SA, Triantafillidou C, Kolilekas L, Markoulaki D, Manali ED. Amiodarone: review of pulmonary effects and toxicity. Drug Saf 2010, 33:539-558.

27. Ohyama KI, Nakajima M, Nakamura S, Shimada $\mathrm{N}$, Yamazaki H, Yokoi T. A significant role of human cytochrome P450 2C8 in amiodarone Ndeethylation: an approach to predict the contribution with relative activity factor. Drug Metab Dispos, 2000; 28:1303-1310.

28. van Herendael H, Dorian. Amiodarone for the treatment and prevention of ventricular fibrillation 
and ventricular tachycardia. Vasc Health Risk Manag, 2010; 6:465-472.

29. Wolkove N, Baltzan M. Amiodarone pulmonary toxicity. Can Respir J, 2009; 16:43-48.

30. Kahaly GJ, Dietlein M, Gärtner R, Mann K, Dralle H. Amiodarone induced thyroid dysfunction. Dtsch Arztebl, 2007; 104:3550-3555.

31. Lahbabi M, Agodad N, Ibrahimi A, Lahlou M, Agodad H. Acute hepatitis secondary to parenteral amiodarone does not preclude subsequent oral therapy. World J Hepatol, 2012; 4:196-198.

32. Siddoway LA. Amiodarone: guidelines for use and monitoring. Am Fam Physician, 2003; 68:21892196.

33. Edwin SB, Jennings DL, Kalus JS. An evaluation of the early pharmacodynamic response after simultaneous initiation of warfarin and amiodarone. J Clin Pharmacol, 2010; 50:693-698.

34. Karimi S, Hough A, Beckey C, Parra D. Results of a safety initiative for patients on concomitant amiodarone and simvastatin therapy in a Veterans Affairs medical center. J Manag Care Pharm, 2010; 16:472-481.

35. Roughead EE, Kalisch LM, Barratt JD, Gilbert AL. Prevalence of potentially hazardous drug interactions amongst Australian veterans. Br J Clin Pharmacol, 2010; 70: 252-257.

36. Shayeganpour A, Jun AS, Brocks DR. Pharmacokinetics of amiodarone in hyperlipidemic and simulated high fat-meal rat models. Biopharm Drug Dispos, 2005; 26:249257.

37. Shayeganpour A, Hamdy DA, Brocks DR. Pharmacokinetics of desethylamiodarone in the rat after its administration as the preformed metabolite, and after administration of amiodarone. Biopharm Drug Dispos, 2008; 29:159-166.

38. US DHHS, FDA, CDER, Guidance for Industry Estimating the maximum safe starting dose in initial clinical trials for therapeutics in adult healthy volunteers. US Department of Health and Human Services, Food and Drug Administration, Center for Drug Evaluation and Research, 2005, Available http:/www.fda.gov/downloads/Drugs/GuidanceC omplianceRegulatoryInformation/Guidances/ucm0 78932.pdf

39. Rodrigues M, Alves G, Ferreira A, Queiroz J, Falcão A. A rapid HPLC method for the simultaneous determination of amiodarone and its major metabolite in rat plasma and tissues: A useful tool for pharmacokinetic studies. J Chromatogr Sci, 2013; 51:361-370.

40. Markowitz JS, von Moltke LL, Donovan JL. Predicting interactions between conventional medications and botanical products on the basis of in vitro investigations. Mol Nutr Food Res, 2008; 52:747-754.

41. Rodrigues M, Alves G, Lourenço N, Falcão A. Herb-drug interaction of Paullinia cupana
(Guarana) seed extract on the pharmacokinetics of amiodarone in rats. Evid Based Complement Alternat Med, 2012; 2012.

42. Rodrigues M, Alves G, Abrantes J, Falcão A. Herb-drug interaction of Fucus vesiculosus extract and amiodarone in rats: a potential risk for reduced bioavailability of amiodarone in clinical practice. Food Chem Toxicol, 2013; 52:121-128.

43. Rodrigues M, Alves G, Falcão A. Investigating herb-drug interactions: The effect of Citrus aurantium fruit extract on the pharmacokinetics of amiodarone in rats. Food Chem Toxicol, 2013; 60:153-159.

44. Tarirai C, Viljoen AM, Hamman JH. Herb-drug pharmacokinetic interactions reviewed. Expert Opin Drug Metab Toxicol, 2010; 6:1515-1538.

45. Martín-Algarra RV, Pascual-Costa RM, Merino M, Casabó VG. Effects of surfactants on amiodarone intestinal absorption. I. Sodium laurylsulfate. Pharm Res, 1994; 11:1042-1047.

46. Martín-Algarra RV, Pascual-Costa RM, Merino M, Casabó VG. Intestinal absorption kinetics of amiodarone in rat small intestine. Biopharm Drug Dispos, 1997; 18:523-532.

47. Elsherbiny ME, El-Kadi AO, Brocks DR. The effect of beta-naphthoflavone on the metabolism of amiodarone by hepatic and extra-hepatic microsomes. Toxicol Lett, 2010; 195:147-154.

48. Shapiro LE, Shear NH. Drug interactions: proteins, pumps, and P-450s. J Am Acad Dermatol, 2002; 47:467-484.

49. Kalitsky-Szirtes J, Shayeganpour A, Brocks DR, Piquette-Miller M. Suppression of drugmetabolizing enzymes and efflux transporters in the intestine of endotoxin-treated rats. Drug Metab Dispos, 2004; 32:20-27.

50. Hidaka M, Fujita K, Ogikubo T, Yamasaki K, Iwakiri T, Okumura M, Kodama H, Arimori K. Potent inhibition by star fruit of human cytochrome P450 3A (CYP3A) activity. Drug Metab Dispos, 2004; 32:581-583.

51. Chatuphonpraset W, Jarukamjorn K. Impact of six fruits-banana, guava, mangosteen, pineapple, ripe mango and ripe papaya on murine hepatic cytochrome P450 activities. J Appl Toxicol, 2012; 32:994-1001.

52. Hidaka M, Nagata M, Kawano Y, Sekiya H, Kai $\mathrm{H}$, Yamasaki K, Okumura M, Arimori K. Inhibitory effects of fruit juices on cytochrome P450 2C9 activity in vitro. Biosci Biotechnol Biochem, 2008; 72:406-411.

53. Oga EF, Sekine S, Shitara Y, Horie T. Pglycoprotein mediated efflux in Caco-2, cell monolayers: the influence of herbals on digoxin transport. J Ethnopharmacol, 2012; 144:612-617.

54. Oga EF, Sekine S, Horie T. Ex vivo and in vivo investigations of the effects of extracts of Vernonia amygdalina, Carica papaya and Tapinanthus sessilifolius on digoxin transport and pharmacokinetics: assessing the significance on rat 
intestinal P-glycoprotein efflux. Drug Metab Pharmacokinet, 2013; 28:314-20.

55. Meng $X$, Mojaverian $P$, Doedée $M$, Lin E, Weinryb I, Chiang ST, Kowey PR. Bioavailability of amiodarone tablets administered with and without food in healthy subjects. Am J Cardiol, 2001; 87:432-435.

56. Matuskova Z, Anzenbacherova E, Vecera R, Tlaskalova-Hogenova H, Kolar M, Anzenbacher P. Administration of a Probiotic can change drug pharmacokinetics: effect of E. coli Nissle 1917 on amiodarone absorption in rats. Plos one, 2014; 9; 87150 .

57. Duru MKC, Amadi BA, Amadi CT, Lele KC, Anudike JC, Chima-Ezika OR, Osuocha K. Toxic effect of Carica papaya bark on body weight, haematology, and some biochemical parameters. Biokemistri, 2012; 24:67-71.

58. Goyal S, Manivannan B, Ansari AS, Jain SC, Lohiya NK. Safety evaluation of long term oral treatment of methanol sub-fraction of seeds of Carica papaya as a male contraceptive in albino rats. J Ethnopharmacol, 2010; 127:286-291. 


\section{ADDITIONAL FILE}

Additional file: Certificate of analysis of Carica papaya extract provided by Bio Serae Laboratories (ref. 420015 - batch 0810960).

\section{ZBio serae}

\section{PAPAYA EXTRACT \\ Carica papaya}

\section{CERTIFICATE OF ANALYSIS}

Ref. 420015 - Batch 0810960

- main characteristics Appearance

Color

Nature

Gamma ray treatment

Taste
Carrier

- ACTIVE INGREDIENTS

Proteolytic activity (NFPU/mg)

- MICROBIOLOGICAL

Enterobacteria (CFU/g)

Escherichia coli (CFU/10g)

Total plate count (CFU/g)

Yeasts and moulds (CFU/g)

Salmonella (CFU/25g)
Staphylococcus aureus (DNAse +) (CFU/10g)

- OTHER ANALYTICAL DATA

Dny matter (\%)

- CONTAMINANTS

Heavy metals (lead eq.) (ppm)

GMO status

- Storage

24 months If kept in a dry and cool place in original intact packing

Manufacturing/analysis date: $\quad 11 / 2008$

Methods

Specifications

Results

Best before:

$11 / 2010$

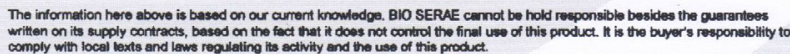

Sio Serae

Bio Serae
Bio Serae

Bio Serae

Bio Serae

Bio Serae

spectrophotometric

fine powder
White to yellowis

tex purified trom papaye complies

$\begin{array}{ll}\text { caracteristic } & \text { complies } \\ \text { Not traated } & \text { complies }\end{array}$

maliodextrin

complies

complies

NF ISU 21528 - 2

Eur. Ph. $2000[\$ 2.6 .13$

NF ISO 4833

AOAC 997.02

BKR 23/04-12/07

Eur. Ph. 2000 [\$2.6.13]

26000

7500

Eur.Ph. $1997\left(\$ 2.2 .32-105^{\circ} \mathrm{C}\right)$

Eur. Ph. 2000 [\$ $\$ 2,4,80]$

1829-1830/2003CE

$<1000$

negative

$<10000$

$<500$

negative

negative

$<10$

$<10$

250

$<10$

negative

Bram, 25-nov-08

98,3

$<10$

Conventional ingredient complies

\section{Qualified batch}

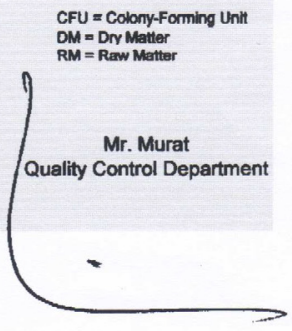

Siege social : No1 avenue de la Preuilhe $\bullet$ Parc Technologique du Lauragais • 11150 Bram • FRANCE

Tel : $33(0) 468767620 \bullet$ Fax : 33 (0)4 68767621 • info@bioserae.com • www.bioserae.com

S.A.S au Capital de 596511 curos • R.C.S. Carcassonne $329581375 \bullet$ Code APE: 10892 • N TV.A. FR 51329581375 